\section{Primer caso de síndrome cardiopulmonar por hantavirus diagnosticado en la Región de Antofagasta, Chile}

\author{
Alcides Zambrano, Roberto Peralta y Mario Cariaga
}

Case Report: first case of hantavirus cardiopulmonary syndrome diagnosed in the Second Region of Antofagasta

Cases of Hantavirus cardiopulmonary syndrome (HCPS) have been reported in Chile between Region V and XI. In our country HCPS is caused by Andes virus. Hantavirus infection is acquired mainly through inhalation of aerosolized rodent fluids. Person to person transmission is considered exceptional. The identified rodent reservoir of the virus extends throughout Region III to XII, and no cases have been reported in the north of Chile. The incubation period is prolonged. We report the first diagnosed patient with HCPS in the north of Chile. In this case we suggest the possibility of person to person transmission.

Key words: hantavirus, cardiopulmonary syndrome.

Palabras clave: Hantavirus, Síndrome Cardiopulmonar.

\section{Introducción}

En Chile, desde 1995 se han confirmado casos del síndrome cardiopulmonar por hantavirus (SCPH) desde Valparaíso hasta Aysén, correspondiendo la mayor incidencia a las regiones de Aysén, Los Lagos, Araucanía y Bío Bío ${ }^{1}$. El agente etiológico del SCPH es un virus ARN del género hantavirus, familia Bunyaviridae, variedad Andes².

El reservorio es el "ratón de cola larga” (Oligoryzomis longicaudatus) el cual se distribuye desde la Región de Atacama (III) hasta la Región de Magallanes $\left(\mathrm{XII}^{\circ}\right)^{2}$. El virus es eliminado por el ratón a través de sus secreciones (saliva, orina y heces) e ingresa al hombre por vía digestiva, cutánea o aérea, siendo esta última la más frecuente ${ }^{1-3}$. La transmisión de persona a persona está documentada, pero se considera excepcional ${ }^{4-6}$.

El SCPH es un cuadro agudo grave con alta letalidad (30-55\%) y sin tratamiento específico ${ }^{7,9}$. El período de incubación puede durar hasta 45 días. Los primeros síntomas son fiebre, mialgias, cefalea y ocasionalmente diarrea; días después aparece la fase de compromiso respiratorio, con disnea progresiva e insuficiencia respiratoria grave ${ }^{7,8}$. Es indispensable la terapia de soporte hemodinámico y manejo de la falla respiratoria en una Unidad de Pacientes Críticos (UPC) ${ }^{9}$.

\section{Caso clínico}

Paciente de 29 años, previamente sano, originario de Concepción y radicado en Antofagasta desde hacía un año. Fue internado en un centro privado de salud por un cuadro de seis días de evolución con fiebre alta, mialgias, cefalea, tos seca y vómitos alimentarios. Tenía antecedentes de haber viajado a la Región del Bío-Bío (zona urbana de Concepción) 36 días antes, donde había tenido contacto con un amigo que estaba cursando con un cuadro diarreico. Al examen físico del ingreso presentaba escasas crepitaciones a la auscultación pulmonar y en la radiografía de tórax no había imágenes de consolidación. En los exámenes de laboratorio destacaba un hemograma con 28.400 leucocitos $/ \mathrm{mm}^{3}$ y desviación a izquierda (63\%

Clínica Regional La Portada.

Recibido: 21 de octubre de 2011 / Aceptado: 16 de junio de 2012

Correspondencia a:

Alcides Zambrano F.

alcidedu@yahoo.es segmentados y 17\% baciliformes), 35.000 plaquetas $/ \mathrm{mm}^{3}$, PCR 7,5 mg/dl ( $\mathrm{N}=0-1)$, LDH y transaminasas elevadas. Al segundo día de hospitalización presentó disnea, polipnea e hipoxemia. Se realizó una TAC de tórax que mostró opacidades pulmonares bilaterales. Se trasladó a la Unidad de Cuidados Intensivos donde se conectó a ventilación mecánica. Evolucionó rápidamente con un SDRA y al tercer día, con una disfunción multiorgánica. Se manejó con corticoesteroides i.v., aminas vasoactivas, antimicrobianos de amplio espectro y oseltamivir empíricos. La serología para VIH y RPC para virus influenza A H1N1, así como los hemocultivos resultaron negativos. Además se solicitó serología para hantavirus al Instituto de Salud Pública. Al sexto día de hospitalización falleció por hipotensión arterial refractaria, oligoanuria, hipoxemia y acidosis metabólica grave. Postmortem se informó una serología positiva para hantavirus (IgM e IgG) ${ }^{10}$.

\section{Discusión}

El caso clínico presentado demuestra la necesidad de considerar al SCHP dentro de los diagnósticos diferenciales de falla respiratoria aguda y SDRA de etiología no clara en el norte de nuestro país, a pesar de no corresponder a la distribución geográfica del reservorio. Esto puede explicarse por el largo período de incubación del SCHP y la alta movilidad actual de la población hacia zonas mineras, en las cuales hay una importante migración de habitantes originarios del sur de Chile, donde el virus Andes es endémico, los cuales potencialmente pueden presentar exposición e infección con el virus ${ }^{6-8}$.

Cabe destacar que el paciente había visitado una zona urbana de Concepción y no se había trasladado a zonas rurales con riesgo de exposición al ratón coli-largo, dejando abierta la posibilidad de la transmisión de persona a persona, lo cual no fue documentado porque no se estudió al eventual caso índice.

\section{Referencias bibliográficas}

1.- Sotomayor V, Olea A M, Labraña M, Castillo C, Ortega C, Riquelme R, et al. Diagnóstico y manejo del síndrome cardiopulmonar por hantavirus. Chile-2007. Rev Chilena Infectol 2009; 26: 68-86.

2.- Medina R A, Torres-Péez F, Galeno H, Navarrete M, Vial P, Palma R E, et al. Ecology, genetic diversity, and phylogeographic structure of Andes virus in humans and rodents in Chile. J Virol 2009; 83: 2446-59.

3.- Täger F M, Vial P C, Castillo C H, Godoy P M, Hjelle B, Ferrés M G. Hantavirus prevalence in the IX Region of Chile. Emerg Infect Dis. 2003; 9: 827-32.

4.- Enría D, Padula P, Segura E L, Pini N, Edelstein A, Posse C R, Weissenbacher M C. Hantavirus pulmonary syndrome in Argentina. Possibility of person to person transmission. Medicina (B Aires) 1996; 56: 709-11.

5.- Padula P J, Edelstein A, Miguel S D, López N M, Rossi C M, Rabinovich $\mathrm{R} D$. Hantavirus pulmonary syndrome outbreak in Argentina: molecular evidence of person-to-person transmission of Andes virus. Virology 1998; 241: 323-30.

6.- Ferrés M, Vial P, Marco C, Yáñez L, Godoy P, Castillo C, et al. Prospective evaluation of household contacts of persons with hantavirus cardiopulmonary syndrome in Chile. J Infect Dis 2007; 195: 1563-71.

7.- Castillo C, Ossa G. Síndrome pulmonar por hantavirus Andes en Chile. Rev Chil Enferm Respir 2002; 18: 35-46.

8.- Vial P A, Valdivieso F, Mertz G, Castillo C, Belmar E, Delgado I, et al. Incubation period of hantavirus cardiopulmonary syndrome. Emerg Infect Dis 2006; 12: 1271-3.

9.- Jonsson C B, Hooper J, Mertz G. Treatment of hantavirus pulmonary syndrome. Antiviral Res 2008; 78: 162-9.

10.- Galeno H, Villagra E, Fernández J, Ramírez E, Mora J. Técnicas diagnósticas de infección humana por hantavirus. Rev Chilena Infectol 2000; 17: 211-5. 